\title{
GAMBARAN DEPRESI POSTPARTUM DI RSKIA SADEWA
}

\author{
Kharisah Diniyah \\ Universitas 'Aisyiyah Yogyakarta Jl. Ringroad Barat No.63 Mlangi, Nogotirto, Gamping, Sleman 55292 email: \\ kharisa188@gmail.com
}

\begin{abstract}
Background: The incidence of postpartum depression develops during pregnancy or after delivery with a prevalence of $10-15 \%$ incidence in developed countries and about $20 \%-40 \%$ in developing countries.

Objective: The purpose of this study was to know the description of the incidence of postpartum depression in RS KiA Sadewa

Methods: The type of this study was cross sectional with postpartum maternal population in 2 weeks postpartum with the number of 78 respondents. The inclusion criteria of postpartum maternal and postnatal cesarean delivery, postpartum visit and / or infant immunization examination in otpatient Rs KIA Sadewa , and willing to be the respondent by signing the informed concent sheet. The preceding criteria for previous depression, delivery of twins, and complications in the mother and / or infant (preeclampsia / eclampsia, postpartum infections, BB $<2500 \mathrm{~g}$ ) would increase the risk of postpartum depression.

Result: The picture of postpartum depression in KIA Sadewa Hospital based on age in respondents <20 years and age 20-35 years found 3 respondents at risk of postpartum depression, based on education on respondents with low education there are 4 respondents at risk of experiencing postpartum depression. Primiparous mother got $5(11,9 \%)$ respondents risked experiencing of postpartum depression, with type of vaginal delivery as many as $4(11,1 \%)$ respondent at risk of postpartum depression

Conclussion: Based on the results of this study concluded that postpartum KIA Sadewa women at risk of experiencing postpartum depression, so that early detection and counseling related penatalksanaan postpartum depression.
\end{abstract}

Key word : Depression, postpartum

\section{PENDAHULUAN}

Kehamilan dan persalinan adalah peristiwa yang membahagiakan dalam hidup, tetapi ada beberapa kasus dapat menjadi momen manakutkan disebabkan perubahan psikologis yang mengakibatkan gangguan suasana hati, kecemasan yang biasa disebut depresi postpartum. Depresi merupakan gangguan mood atau perasaan, dimana kondisi tersebut dapat menimbulkan gangguan aktivitas pada individu. ${ }^{1}$

$$
\text { Prevalensi kejadian depresi }
$$

postpartum 10-15 \% di negara maju dan sekitar 20\%-40\% di negara berkembang. ${ }^{2} \mathrm{Di}$ Yogyakarta prevalensi kejadian depresi postpartum sebesar 35,2 \%. ${ }^{3}$ Depresi postpartum mempunyai dampak negatif yang signifikan pada kognitif, sosial dan perkembangan anak-anak. ${ }^{4}$ Efek depresi bukan saja pada ibu, tetapi bayi pada ibu depresi akan mengalami keterlambatan kognitive, psikologi, neurologi dan perkembangan motorik. ${ }^{5} \mathrm{Hal}$ tersebut sangat penting untuk mengidentifikasi faktor risiko depresi postpartum terutama di negara berkembang dengan jumlah populasi besar dan masih muda serta tingginya angka keseburan. $^{2}$

Faktor penyebab depresi postpartum diantaranya adalah riwayat depresi sebelumnya, dukungan sosial, hubungan pernikahan, faktor obstetri (sectio cesaria, 
persalinan dengan alat), meskipun faktor obstetri tidak banyak yang memberikan perhatian. ${ }^{6}$ Di Indonesia sendiri belum ada yang melaporkan data kejadian depresi postpartum, beberapa penelitian sudah dilakukan untuk mengetahui faktor risiko kejadian depresi postpartum, antara lain penelitian yang dilakukan oleh Humayun et al di dapatkan hasil riwayat depresi sebelumnya, kekerasan rumah tangga, kurangnya dukungan sosial merupakan faktor signifikan terhadap kejadian depresi postpartum. $^{7}$ Faktor sosiodemografi mempunyai hubungan yang signifikan dengan kejadian depresi postpartum. ${ }^{8}$ Andajani meneliti gambaran ungkapan perasaan wanita Indonesia didapatkan bahwa hubungan perkawainan, kurangnya dukungan sosial, faktor sosiodemografi menggambarkan perasaan terkait depresi postpartum. $^{9}$

$\begin{array}{lrrr}\text { Deteksi } & \text { dini } & \text { kejdian } & \text { depresi } \\ \text { postpartum dapat dilakukan } & \text { dengan }\end{array}$ menggunakan lembar Edinburgh Postnatal Depression Scale (EPDS) yang diisi sendiri oleh pasien dan dapat digunakan dengan mudah. $^{10}$ Meskipun bukan alat untuk mendiagnosa, skore lebih dari 13 diprediksi depresi postpartum dengan nilai sensitivitas $86 \%$ dan spesifitas $78 \%$ yang dlakukan di Indonesia. $^{9}$

Tujuan penelitian ini adalah untuk mengetahui gambaran kejadian depresi pada ibu post partum di RS KIA Sadewa.

\section{BAHAN DAN CARA PENELITIAN}

Metode penelitian deskriptif dengan pendekatan kuantitatif. Populasi dalam penelitian ini adalah ibu nifas yang melahirkan secara spontan maupun malahirkan secara sectio cesaria yang berkunjung di RS KIA Sadewa. Teknik sampling yang digunakan dengan consequtive sampling. Sampel dalam penelitian ini berjumlah 78 responden dengan kriteria inklusi ibu dalam 2 minggu masa nifas yang melakukan kunjungan di RSKIA Sadewa, melahirkan secara normal dan yang melahirkan secara sectio cesarea, melakukan kunjungan nifas dan atau pemeriksaan imunisasi bayi di poliklinik RS KIA Sadewa, dan bersedia menjadi responden dengan menandatangi lembar informed concent. Kriteria eksklusi penelitian yaitu mempunyai riwayat depresi sebelumnya, melahirkan bayi kembar, dan komplikasi pada ibu dan atau bayi (pre eklamsi/eklamsia, infeksi masa postpartum, $\mathrm{BB}<2500$ gr karena akan meningkatkan risiko depresi postpartum. Intrument dalam penelitian menggunakan kuesioner EPDS dan kuesioner data demografi. Analisa data dalam penelitian ini menggunakan analisa univariat.

\section{HASIL DAN PEMBAHASAN}

Berdasarkan hasil penelitian diketahui bahwa responden penelitian didapatkan 3 responden berumur $<20$ tahun dan pada 
umur 20-35 tahun mengalami depresi. Responden dengan pendidikan rendah didapatkan $4(28,6 \%)$ mengalami depresi dan $2(3,1 \%)$ responden dengan pendidikan tinggi. Pada ibu primipara didapatkan 5 $(11,9 \%)$ responden mengalami depresi dan 1 $(4,8 \%)$ responden dengan paritas multigravida mengalami depresi). Jenis persalinan dengan sectio cesaria di dapatkan $2(4,8 \%)$ responden mengalami depresi dan per salinan pervaginan didapatkan $4(11,1 \%)$ responden mengalami depresi. Hal tersebut sesuai dengan tabel 1.

Tabel 1. Karakteristik Responden

\begin{tabular}{|c|c|c|c|c|c|c|}
\hline & & & & ejadis & dep & resi \\
\hline Variabel & $\mathbf{n}$ & $\%$ & & oresi & & $\begin{array}{l}\text { dak } \\
\text { resi }\end{array}$ \\
\hline Umur & & & $f$ & $\%$ & $f$ & $\%$ \\
\hline$<20$ & 3 & 3,8 & 3 & 100 & 0 & 0 \\
\hline 20-35 tahun & 66 & 84,6 & 3 & 4,5 & 63 & 9,5 \\
\hline$>35$ tahun & 9 & 11,5 & 0 & 0 & 9 & 100 \\
\hline Pendidikan & & & & & & \\
\hline Rendah & 14 & 17,9 & 4 & 28,6 & 10 & 71,4 \\
\hline Tinggi & 64 & 82,1 & 2 & 3,1 & 62 & 96,9 \\
\hline Pekerjaan & & & & & & \\
\hline Tidak Bekerja & 36 & 46,2 & 3 & 8,3 & 33 & 91,7 \\
\hline Bekerja & 42 & 53,9 & 3 & 7,1 & 39 & 92,9 \\
\hline Paritas & & & & & & \\
\hline Multipara & 36 & 46,2 & 1 & 2,8 & 35 & 97,2 \\
\hline Primipara & 42 & 53,8 & 5 & 11.9 & 37 & 88,1 \\
\hline $\begin{array}{l}\text { Jenis } \\
\text { Persalinan }\end{array}$ & & & & & & \\
\hline & 42 & 53,8 & 2 & 4,8 & 40 & 95,2 \\
\hline Pervagina & 36 & 46,2 & 4 & 11,1 & 32 & 88,9 \\
\hline $\begin{array}{l}\text { Jenis } \\
\text { Kelamin }\end{array}$ & & & & & & \\
\hline Perempuan & 38 & 48,7 & 3 & 7,9 & 35 & 92.2 \\
\hline Laki-laki & 39 & 50 & 3 & 7,7 & 36 & 92.3 \\
\hline Pen & & ni be & & an $r$ & $0 n$ & tahui \\
\hline gambaran & & $\mathrm{pc}$ & r & Im & $\mathrm{R}$ & $\mathrm{KIA}$ \\
\hline Sadewa. & a & si & & si & t & SKIA \\
\hline $\begin{array}{l}\text { Sadewa se } \\
\text { depresi pos }\end{array}$ & sar & 7,7\%. & $D_{r n}$ & iala & & ian \\
\hline
\end{tabular}

beda, hal tersebut bergantung pada penentuan nilai cut off, waktu mendiagnosa. Penelitian yang dilakukan oleh Prayoga et al di Denpasar di dapatkan prevalensi kejadian depresi postpartum 20,5\%. ${ }^{11}$

Faktor risiko depresi postpartum diantaranya adalah sosio-demografi yang meliputi umur, pendidikan dan pekerjaan, dan cara persalinan. ${ }^{2}$ Penelitian ini didapatkan bahwa usia yang mengalami depresi pada rentang usia 20-35 tahun dan pada umur kurang dari 30 tahun mengalami depresi sebanyak 3 responden, sehingga didapatkan hasil bahwa umur tidak berhubungan dengan depresi postpartum. Responden dengan umur berapaun bisa mengalami kejadian depresi postpartum. Penelitian ini sesuai dengan penelitian yang dilakukan oleh Burgut et al bahwa umur tidak berhubungan dengan depresi postpartum. ${ }^{2}$

Hasil penelitian ini didapatkan berdasarkan usia bahwa mayoritas responden berusia reproduksi dan didapatkan 3 responden dan pada umur $<20$ tahun didapatkan 3 responden mengalami depresi. Penelitian lain didapatkan bahwa umur berhubungan dengan depresi pascasalin dengan kekuatan hubungan lemah. $^{12}$ Berbeda dengan penelitian yang dilakukan oleh Humayun et al didapatkan kelompok umur $<20$ tahun atau $>35$ tahun berisiko terjadi depresi postpartum tetapi lebih berisiko pada ibu dengan usia muda. ${ }^{7}$ Pada ibu usia muda permasalahan keuangan, kehamilan tidak diinginkan dan 
kurangnya dukungan dari pasangan. Usia tersebut merupakan usia berisiko bagi perempuan untuk melahirkan bayi. Menurut BKKBN rentang usia 20-35 tahun adalah usia ideal perempuan untuk melahirkan. Penelitian yang dilakukan oleh Yanti didapatkan umur berhubungan dengan depresi postpartum. ${ }^{13}$ Ibu yang berumur lebih muda menunjukan kejadian depresi postpartum. Usia sering dikaitkan dengan kematangan perkembangan dan kematangan individu. Stewart et al dalam literatur review dari 26 penelitian dengan responden lebih dari 10.000 didapatkan bahwa umur tidak berhubungan dengan depresi postpartum. ${ }^{14}$

$$
\text { Hasil penelitian berdasarkan }
$$

pendidikan didapatkan 4 responden mengalami depresi pada ibu dengan pendidikan rendah. Pendidikan berpengaruh terhadap kesiapan dan pengetahuan dalam menjalani kehamilan dan persalinan. Penelitian yang dilakukan Soep didapatkan $51,7 \%$ ibu dengan pendidikan sedang mengalami depresi . Penelitian Burgut et al yang dilakukan di Qatar didapatkan bahwa pendidikan berhubungan dengan kejadian depresi postpartum. ${ }^{2}$ Berbeda dengan penelitian yang dilakukan Ibrahim \& Ikhsan didapatkan kejadian depresi postpartum didapatkan pada ibu dengan pendidikan tinggi. ${ }^{15}$ Tekanan sosial dan konflik peran sering dialami oleh ibu dengan pendidikan tinggi, antara bekerja atau karir dengan peran sebagai ibu rumah tangga (Kartono, 1992). Literatur review yang dilakukan oleh Stewart et al pada 10 penelitian dan lebih dari 7.000 responden didapatkan bahwa tingkat pendidikan tidak berhubungan dengan depresi postpartum. ${ }^{14}$

Penelitian ini didapatkan bahwa sebagian besar responden adalah ibu rumah tangga. Penelitian ini didapatkan 3 responden ibu yang tidak bekerja dan ibu yang bekerja mengalami depresi. Penelitian yang dilakukan oleh Burgut et al didapatkan pekerjaan berhubungan dengan depresi postpartum. ${ }^{2}$ Penelitian yang dilakukan oleh Wahyuni et al pada ibu postpartum di wilayah kerja Puskesmas Klaten didapatkan ibu yang tidak bekerja berisiko terjadi depresi 10 kali bila dibandingkan dengan ibu yang bekerja. $^{16}$

Dalam penelitian ini didapatkan 4 responden pada primigravida berisiko mengalami depresi postpartum dan 1 responden pada ibu multigravida berisiko mengalami depresi postpartum. Penelitian ini sesuai dengan Fitriana \& Nurbaeti bahwa paritas berhubungan dengan kejadian depresi postpartum. ${ }^{17}$ Sedang penelitian yang dilakukan oleh Yanti didapatkan bahwa ibu primipara berisiko terjadi depresi postpartum. ${ }^{13}$ lbu primipara baru melahirkan pertama kali dan belum mempunyai kesiapan menjadi seorang ibu. Berdasarkan hasil penelitian didapatkan pada ibu primipara sebgian besar masih bingung dalam merawat bayi, lebih beradaptasi dalam menyesuiakn peran sebagai seorang ibu. Literatur review yang dilakukan oleh Stewart et al 
berdasarkan 7 penelitian dengan sampel lebih dari 7.000 didapatkan paritas tidak berhubungan dengan kejadian depresi postpartum. ${ }^{14}$

Pada penelitian ini didapatkan bahwa sebagian besar responden dengan persalinan SC. Faktor penyebab depresi postpartum salah satunya adalah faktor obstetri yaitu jenis persalinan. Penelitian sebelumnya banyak menjelaskan hubungan jenis persalinan dengan kejadian depresi postpartum. Beberapa penelitian mengungkapkan terdapat hubungan jenis persalinann dengan depresi postpartum ${ }^{15}$ dan tidak terdapat hubungan jenis persalinan dengan depresi postpartum. ${ }^{14,16}$ Penelitian ini didapatkan 4 responden pada persalinan pervagina berisiko megalami depresi postpartum. Lamanya persalinan dan intervensi medis selama proses persalinan berhubungan terhadap kejadian depresi postpartum. Menurut Swain dalam Ibrahim \& Ikhsan pada pemeriksaan Scan Magnetic Resonance Imaging (MRI) terjadi peningkatan aktivitas otakyang berhubungan dengan emosi, motivasi dan kebiasaan. ${ }^{15}$ Pada pasien dengan riwayat SC dapat menimbulkan tauma fisik karena adanya perlukaan pada rahim serta aktivitas ibu terbatas dan membutuhkan waktu untuk penyembuhan luka. Dalam penelitian ini persalinan dengan SC tinggi, berbagai indikasi medis sampai dengan indikasi permintaan pasien karena tidak tahan sakit.

\section{KESIMPULAN}

Berdasarkan hasil penelitian tersebut dapat disimpulkan bahwa kejadian depresi postpartum di RS KIA sadewa 7,7\%. Ibu nifas di RS KIA Sadewa berisiko mengalami depresi postpartum. Perlu diberikan deteksi dini kejadian depresi postpartum dengan menggunakan kuesioner EPDS dan diberikan penyuluhan pada semua ibu postpartum untuk mencegah depresi postpartum.

\section{KEPUSTAKAAN}

1. Depkes RI. Pedoman Penggolongan Dan Diagnosis Gangguan Jiwa Di Indonesia Cetakan Pertama. Jakarta: Depkes Rl; 1993.

2. Burgut FT, Bener A, Ghuloum S, Sheikh J. A study of postpartum depression and maternal risk factors in Qatar. $J$ Psychosom Obstet Gynecol. 2013;8942(2):90-97. doi:10.3109/0167482X.2013.786036.

3. Wahyuntari E, Hakimi M, Ismarwati I. Relationship of Social Support with Postpartum Depression in Sadewa Hospital Yogyakarta. Int J Sci Basic Appl Res. 2017;35:76-84.

4. Borra C, lacovou M, Sevilla A. New Evidence on Breastfeeding and Postpartum Depression: The Importance of Understanding Women's Intentions. 2015:897-907. doi:10.1007/s10995-0141591-Z.

5. APA \& ACOG. Guidelines for Perinatal Care. American Academy Of Pediatric and The American College Of Obstetricians an Gynecologist; 2012.

6. Robertson E, Ph D, Grace S, Ph D, Wallington T, Stewart DE. Antenatal risk factors for postpartum depression: a synthesis of recent literature. Gen Hosp Psychiatry. 2004;26(4):289-295. doi:http//dx.doi.org/10.1016/j.genhosppsy ch.2004.02.006.

7. Humayun, Haider, Imran, Iqbal, Humayun. Antenatal depression and its 
predictors in Lahore, Pakistan. East Mediterr Heal J. 2013;19(4):327-332. http://www.ncbi.nlm.nih.gov/pubmed/2388 2957.

8. Thurgood S, Avery DM. Postpartum Depression ( PPD ). Am J Clin Med. 2009;6:17-22.

9. Andajani, Manderson L, Astbury J. Complex emotions, complex problems: Understanding the experiences of perinatal depression among new mothers in urban Indonesia. Cult Med Psychiatry. 2007;31(1):101-122. doi:10.1007/s11013006-9040-0.

10. Cox JL, Sagovsky JMHR. Detection of Postnatal Depression Development of the 10-item Edinburgh Postnatal Depression Scale. Br J Psychiatry. 1987;150:782787.

11. Prayoga IK, Dira A, Ayu A, Wahyuni S. Prevalensi Dan Faktor Risiko Depresi Post Partum Di Kota Denpasar Menggunakan Edinburgh Posnatal Depression Scale. E-Jurnal Med. 2016;5(7):5-9.

12. Gondo HK. Skrining Edinburgh Postnatal Depression Scale (EPDS) Pada Postpartum Blues. $J \mathrm{llm}$ Kedokt. 2012;1(2):7-19.

13. Yanti L. Hubungan Antara Umur, Paritas, Dengan Depresi Postpartum di Kelurahan Teluk Wilayah Puskesmas Purwokerto Selatan. J Kesehat Kususma Husada. 2014;2(2):88-96.

14. Stewart DE, Robertson E, Phil M, Dennis C, Grace SL, Wallington T. Postpartum Depression: Literatur Review Of Risk Factors And Intervention. Toronto Public Heal. 2003;(October).

15. Ibrahim F, Ikhsan M. Faktor-Faktor yang Berhubungan Dengan Depresi Postpartum Di RSIA Pertiwi Makasar Tahun 2012. 2012;(82).

16. Wahyuni S, Murwati, Supiati. Faktor Internal Dan Eksternal Yang Mempengaruhi Depresi Postpartum. J Terpadu ilmu Kesehat. 2014;3 No.2:131137.

17. Fitriana LA, Nurbaeti S. Gambaran Kejadian Postpartum Blues Pada lbu. 2015. 